\title{
Evaluation of bidirectional interstimulus interval (ISI) shift in auditory delay eye-blink conditioning in healthy humans
}

\author{
Adam B. Steinmetz • Patrick D. Skosnik • \\ Chad R. Edwards • Amanda R. Bolbecker • \\ Joseph E. Steinmetz • William P. Hetrick
}

Published online: 12 May 2011

(C) Psychonomic Society, Inc. 2011

\begin{abstract}
Delay eye-blink conditioning is an associative learning task that can be utilized to probe the functional integrity of the cerebellum and related neural circuits. Typically, a single interstimulus interval (ISI) is utilized, and the amplitude of the conditioned response (CR) is the primary dependent variable. To study the timing of the CR, an ISI shift can be introduced (e.g., shifting the ISI from 350 to $850 \mathrm{~ms}$ ). In each phase, a conditioned stimulus (e.g., a 400 - or $900-\mathrm{ms}$ tone) coterminates with a 50 -ms corneal air puff unconditioned stimulus. The ability of a subject to adjust the $\mathrm{CR}$ to the changing ISI constitutes a critical timing shift. The feasibility of this procedure was examined in healthy human participants $(N=58)$ using a bidirectional ISI shift procedure while cortical event-related brain potentials were measured. CR acquisition was faster and the responses better timed when a short ISI was used. After the ISI shift, additional training was necessary to allow asymptotic responding at the new ISI. Interestingly, auditory event-related potentials to the CR were not associated with conditioning measures at either ISI.
\end{abstract}

\footnotetext{
A. B. Steinmetz $\cdot$ C. R. Edwards · A. R. Bolbecker

W. P. Hetrick $(\bowtie)$

Department of Psychological and Brain Sciences,

Indiana University,

1101 East 10th Street,

Bloomington, IN 47405, USA

e-mail: whetrick@indiana.edu

P. D. Skosnik

Department of Psychiatry, Yale School of Medicine,

300 George Street, Suite 901,

New Haven, CT 06511, USA

\section{J. E. Steinmetz}

Department of Psychology, Ohio State University,

225 Psychology Building, 1835 Neil Avenue,

Columbus, OH 43210, USA
}

Keywords Human learning · Associative learning · Acquisition - Classical conditioning - Temporal processing . Timing

Classical eye-blink conditioning (EBC) is a cerebellardependent associative learning task that has been used to probe the functional integrity of the cerebellum in both human and nonhuman mammals. In the traditional delay form of this task, developed by Gormezano, Schneiderman, Deaux, and Fuentes (1962), a conditioned stimulus (CS; e. g., a tone) is paired with a coterminating unconditioned stimulus (US; e.g., a corneal air puff). Repeated CS-US pairings elicit development of a conditioned response (CR), which peaks in amplitude in healthy subjects around the time of the US presentation. The neural circuitry governing $\mathrm{CR}$ acquisition and timing in the delay EBC procedure is well understood and relatively discrete, limited mostly to the cerebellar cortex, cerebellar deep nuclei, and brain stem (Christian \& Thompson, 2003; Steinmetz, 2000; Thompson \& Steinmetz, 2009). In addition, the cerebellar networks mediating this form of associative learning appear to be conserved across species (e.g., rat-Rogers, Britton, \& Steinmetz, 2001; human-Gerwig, Kolb, \& Timmann, 2007). Thus, a number of groups have utilized EBC as an index of human cerebellar function in several developmental and clinical conditions, including aging (Woodruff-Pak, Jaeger, Gorman, \& Wesnes, 1999; Woodruff-Pak \& Thompson, 1988), autism (Sears, Finn, \& Steinmetz, 1994), psychopathology (Bolbecker, Mehta, Edwards, et al., 2009; Bolbecker, Mehta, Johannesen, et al., 2009; Brown et al., 2005), and drug abuse (Skosnik et al., 2007).

Research over the past 25 years has strongly supported the role of the cerebellar cortex and deep nuclei in the acquisition and timing of the $\mathrm{CR}$ during delay EBC. In 
relation to learning and behavioral occurrence of the $\mathrm{CR}$, a number of lesion, neural unit recording, and reversible inactivation studies have provided compelling evidence that the memory trace for delay EBC resides in regions of the cerebellar deep nuclei (anterior lateral interpositus nucleus, located ipsilateral to the trained eye; for reviews, see Christian \& Thompson, 2003; Steinmetz, 2000; Thompson \& Steinmetz, 2009). Although a number of human studies have investigated delay EBC deficits after insult to the deep nuclei (Schugens, Topka, \& Daum, 2000), it has been difficult to rule out the possibility that cerebellar cortical damage has not also occurred (Daum et al., 1993; Lye, O'Boyle, Ramsden, \& Schady, 1988; McGlinchey-Berroth et al., 1995; Solomon, Stowe, \& Pendlbeury, 1989; Topka, Valls-Sole, Massaquoi, \& Hallett, 1993; Woodruff-Pak, 1997).

Several studies have identified a role of the cerebellar cortex in the timing and gain of CRs (Lavond \& Steinmetz, 1989; Logan, 1991; McCormick \& Thompson, 1984; Perrett, Ruiz, \& Mauk, 1993). Manipulations of the cerebellar cortex by ablation, chemical inactivation, elimination of Purkinje cells genetically or chemically, or disrupting long-term depression (LTD) mechanisms that occur in the cortex have caused a severe impairment in acquisition of delay EBC (Attwell, Rahman, \& Yeo, 2001; Chen, Bao, S., Lockard, Kim, \& Thompson, 1996; Chen, Bao, \& Thompson, 1999; Garcia, Steele, \& Mauk, 1999; Lavond \& Steinmetz, 1989; Nolan \& Freeman, 2006; Steinmetz \& Freeman, 2010; Thompson \& Steinmetz, 2009). For example, Perrett et al. (1993) demonstrated that cerebellar cortical lesions in rabbits resulted in maladaptive short-latency CRs in a discrimination delay EBC paradigm. More recently, Vogel, Amundson, Lindquist, and Steinmetz (2009) found that infusions of picrotoxin into the deep nuclei of rabbits, which disrupt cortical activity, had more effect at longer ISIs than at shorter ISIs. In humans, the involvement of the cerebellar cortex in modulating the CR has been supported using positron emission tomography (Blaxton et al., 1996; Logan \& Grafton, 1995), functional magnetic resonance imaging (Dimitrova et al., 2002; Ramnani, Toni, Josephs, Ashburner, \& Passingham, 1999), and clinical samples with cerebellar insults (Daum et al., 1993; Woodruff-Pak, Papka, \& Ivry, 1996). Gerwig et al. (2005) demonstrated that in cerebellar patients, greater damage to the anterior lobe was significantly correlated with larger timing deficits during delay EBC. One possible conclusion that can be drawn from these studies is that a dynamic interaction between the cerebellar cortex and deep nuclei underlies both the acquisition and the accurate timing of the $\mathrm{CR}$, with the cortex potentially playing a crucial role in modulating the timing of the response.

Most studies aiming to investigate the timing of CRs during EBC, particularly in humans, have simply examined peak or onset latencies during standard delay EBC procedures. Another method of assessing the adaptive timing and temporal flexibility of CRs in EBC has involved use of an interstimulus interval (ISI) shift. This technique is a variation of the classical delay EBC procedure, in which the ISI between the CS and US onsets is altered or shifted within subjects. In a representative ISI shift procedure, a shorter CS (e.g., $400 \mathrm{~ms}$ ) is changed to a longer CS (e.g., $900 \mathrm{~ms}$ ). This change may occur unexpectedly, or after a brief intermission, and the ability to adjust the CR latency to the changing ISI constitutes a test of CR timing shift.

Eye-blink conditioning ISI shift studies in nonhuman mammals have consistently found that, regardless of whether the CS is a traditional tone or subthreshold microstimulation of the interpositus nucleus or mossy fiber afferents, a well-established CR at a specific CS-US interval will adapt to a novel ISI (Coleman \& Gormezano, 1971; Leonard \& Theios, 1967; Poulos \& Thompson, 2004; Steinmetz 1990a, b). Interestingly, the CR adaptation (recovery of percentage of CRs and adjustment of CR latencies after the shift) in nonhuman species appears to occur more effectively when the initial ISI is within the optimum CS latency range $(200-500 \mathrm{~ms})$ and is shorter than the postshift ISI (Poulos \& Thompson, 2004; Steinmetz 1990a, b). With respect to human studies, there is a surprising paucity of contemporary experiments using the ISI shift procedure. Early examinations of ISI shift in humans were consistent with nonhuman animal studies in showing that CR latency and acquisition adapt to changes in the ISI (Boneau, 1958; Boneau, King, \& Kimble, 1956; Ebel \& Prokasy, 1963). For example, Boneau shifted the ISI from 500 to 1,000 or $1,500 \mathrm{~ms}$ using a light CS with young adults. A decrease in the percentage of CRs was witnessed after the ISI shift, although a larger decrease occurred with the 1,500-ms CS. The CR latencies adjusted according to the ISI shift, moving from an earlier response to a later response. Given the utility of EBC in evaluating cerebellar function, revisiting the ISI shift methodology is warranted. Further refinement of this technique for use in humans may prove highly valuable with respect to evaluations of the cerebellum in patient populations, which may further dissociate $\mathrm{CR}$ timing from $\mathrm{CR}$ acquisition deficits.

Therefore, in order to extend the knowledge derived from human studies of the ISI shift procedure, the present experiment was designed to examine the effects of an ISI shift manipulation on EBC in healthy humans using a bidirectional auditory ISI shift procedure. Four conditions, two shifting (short to long and long to short) and two stable (short to short and long to long) were employed. In addition, concomitant frontocentral electroencephalographic (EEG) recording data were made in order to assess eventrelated potentials (ERPs) to the tone CS during EBC. It has recently been shown that a tone CS during EBC elicits a 
robust N100-P200 ERP complex (Edwards et al., 2008; Skosnik et al., 2007), which is known to be generated in the auditory cortex and is sensitive to attention allocation (Coull, 1998; Hillyard, Hink, Schwent, \& Picton, 1973). In animals, the auditory cortex has been shown to exhibit electrophysiological changes that are related to conditioning (Kraus \& Disterhoft, 1982). While the auditory cortex doesn't appear to be essential for EBC in animals (Oakley \& Russell, 1977), it has been suggested that auditory cortical input may contribute to conditioning, particularly when more complex CS processing is required (Knowlton, Thompson, \& Thompson, 1993). Hence, these EEG measures were included because it is unknown whether CS processing in the human auditory cortex is meaningfully associated with measures of conditioned learning.

Following prior behavioral ISI shift studies, the central hypothesis was that the rate of conditioned responses would drop immediately after a shift in the ISI (e.g., from short to long), which would then be followed by a steady increase in the rate of CRs to preshift levels, regardless of the directionality of the shift. Additionally, it was expected that $\mathrm{CR}$ latencies would adapt to the appropriate temporal interval following the ISI shift.

\section{Method}

\section{Participants}

A total of 27 male (mean age $22.04 \pm 3.31$ ) and 31 female (mean age $20.00 \pm 2.22$ ) participants were recruited from the local university community via fliers and paid for their participation. Prospective participants provided verbal consent and were screened over the phone to ensure that they were between the ages of 18 and 35, had no history of neurological problems such as strokes or seizures, no history of learning disabilities, and no illicit drug use, and had normal or corrected-to-normal vision. After providing written informed consent, participants completed an audiology test to ensure that their hearing was within normal range (above $20 \mathrm{~dB}$ at 500, 1000, and $2000 \mathrm{~Hz}$ ).

\section{Delay eye-blink conditioning ISI shift paradigm}

Two versions of the delay eye-blink conditioning task were employed. One version utilized a short, 350-ms CS-US delay ISI, and a second version used a long, 850-ms ISI. These values represent the time between the CS and US onsets. Participants completed one of two experimental conditions: either a nonshift condition, where two consecutive EBC sessions had identical ISIs (e.g., short to short $[N=11]$ or long to long $[N=11])$ or a shift condition, where an ISI shift occurred from Session 1 to Session 2 (e.g., short to long $[N=18]$ or long to short $[N=18]$ ). For all participants, the EBC procedure was preceded by the presentation of 8 US-alone air puff trials used to examine baseline startle responsiveness to the air puff. Both the preshift and postshift sessions were composed of 10 blocks of 10 CS-US paired trials; thus, a total of 20 trial blocks were presented across the two sessions. The CS was a 400 or $900-\mathrm{ms}(1000 \mathrm{~Hz}, 80 \mathrm{~dB}$ SPL) tone that coterminated with a US air puff $(50 \mathrm{~ms}, 10$ pounds per square inch at the source). A 5-min break occurred between the two EBC sessions to minimize participant fatigue. The participants were not aware of the possible shift in ISI.

In order to maintain attention throughout the procedure, participants were asked to rate the pleasantness of neutral pictures selected from the International Affective Picture System (Lang \& Greenwald, 1988) on a scale from 1 to 10 using a button pad. An image was presented $2.4 \mathrm{~s}$ after US termination for $2 \mathrm{~s}$. The intertrial interval of the paired CSUS stimuli was $15 \mathrm{~s}( \pm 2 \mathrm{~s})$. Subjects were observed through a closed-circuit monitor in order to assess wakefulness. The experiment was briefly suspended if signs of fatigue were observed, so that the examiner could interact with the participant.

\section{Eye-blink recording procedure}

Eye blinks were recorded using pairs of bipolar electromyogram (EMG) electrodes (4-mm $\mathrm{Ag} / \mathrm{AgCl}$ ) placed on the orbicularis palpebrarum muscle below the left eye. These electrodes were placed within $1 \mathrm{~cm}$ of the lower eyelid, separated by $1 \mathrm{~cm}$, and were set at equal distances from the center of the eye, as defined by pupil position while the participant gazed straight ahead. A ground electrode was placed on the forehead. The air puff was presented $1 \mathrm{~cm}$ from the inner canthus on the left eye via copper tubing (1/ 16-in. diameter) attached to eyeglass rims worn by the participant. Foam ear inserts were used for the presentation of the CS tone. Data were recorded continuously at $2.5 \mathrm{kHz}$ with a Sensorium, Inc., bioamplifier (high-pass filter = $1 \mathrm{~Hz}, 12 \mathrm{~dB} /$ octave; low-pass filter $=300 \mathrm{~Hz}$, eighth-order elliptic; gain $=2,500$ ) and stored for offline analysis.

EBC data analysis

The data were segmented into equal 1,650-ms epochs, which included $1,000 \mathrm{~ms}$ of pre-CS and $250 \mathrm{~ms}$ of post-US EMG activity in the 400-ms CS condition. In the 900-ms CS condition, $500 \mathrm{~ms}$ of pre-CS and $250 \mathrm{~ms}$ of post-US EMG activity were available for analysis. Baseline activity was defined as activity occurring during the $125-\mathrm{ms}$ window preceding CS onset. The CR window was defined as the period $250 \mathrm{~ms}$ before US onset. A CR was defined as EMG activity that occurred in the $\mathrm{CR}$ window and 
exceeded five standard deviations $(S D \mathrm{~s})$ from the baseline activity. Trials with spontaneous blinks (also defined by activity $5 S D$ s above the baseline criterion) occurring 25$75 \mathrm{~ms}$ post-CS-onset were excluded from analysis. Identical $\mathrm{CR}$ scoring procedures were used for the long-delay condition, including the use of a $250-\mathrm{ms}$ CR window just prior to US onset.

A 250-ms CR window was used to assess conditioning for both the short and long ISIs. It has been reported that most CRs occur within 300-400 ms before US onset (Spence \& Ross, 1959), meaning that, for long CSs, CR windows that are more closely aligned to US onset may be preferred over windows that span the entire ISI period. Longer CS windows also increase the risk of inflating CR estimates due to spontaneous blinks, as compared to shorter $\mathrm{CR}$ windows. For these reasons, we chose to use a short, 250-ms window across both the long- and short-ISI conditions for this experiment. CR windows have also been held constant in previous studies examining ISIs of multiple durations (Finkbiner \& Woodruff-Pak, 1991). In such cases, it has been reported that keeping this window constant eliminated very few CRs and offered the benefit of reducing the chance that noise artifacts would contaminate the data. In order to confirm this observation with the present data set, the 250-ms CR window was compared to a 750-ms CR window. A 2 (CR window length: 250 vs. $750 \mathrm{~ms}) \times 10$ (block) repeated measures ANOVA was performed. The differences were not significant $(p=.28)$. Therefore, in the following analyses, a 250-ms CR analysis window was used across all ISI conditions to maximize methodological consistency and minimize potential differential influences of spontaneous blinks and other EMG artifacts, which have a higher probability of occurring in longer analysis windows.

\section{EEG recording and data analysis}

EEG data were concurrently collected during the EBC paradigm from the frontocentral electrode sites where auditory ERPs are maximal $(\mathrm{Fz}, \mathrm{FCz}$, and $\mathrm{Cz}$ ) using gold cup electrodes (Grass Technologies, West Warwick, RI). The EEG was recorded continuously (high-pass filter = $0.02 \mathrm{~Hz}, 12 \mathrm{~dB} /$ octave; low-pass filter $=300 \mathrm{~Hz}$, eighthorder elliptic; gain $=10,000$, sampling rate $=2.5 \mathrm{kHz}$ ) from the scalp with a nose reference, along with additional electrodes to record the vertical electrooculogram (VEOG). The recorded EEG was segmented into epochs consisting of either the 400 - or $900-\mathrm{ms}$ stimulus presentation, along with $100 \mathrm{~ms}$ of prestimulus activity. Any epoch containing a voltage greater than $\pm 100 \mu \mathrm{V}$ after baseline correction was excluded. Ocular artifact correction was applied using the algorithm of Gratton, Coles, and Donchin (1983), and averages were computed for each condition using commer- cially available software (Vision Analyzer, Brain Products $\mathrm{GmbH}$, Germany). For analysis of the evoked responses (N100 and P200), epochs were low-pass filtered at $15 \mathrm{~Hz}$ (24 dB/octave) prior to averaging and were baseline corrected (100-ms prestimulus baseline) after averaging. The time window for the N100 component was defined as the largest negative peak occurring between 70 and $150 \mathrm{~ms}$ after onset of the tone CS, while the P200 was defined as the largest positive peak between 170 and $250 \mathrm{~ms}$. Peak amplitude and latency values were used as the dependent measures and were obtained for each electrode within the time window of interest using an automated algorithm (Vision Analyzer, Brain Products GmbH, Germany).

\section{Statistical analysis}

The primary dependent measures for the eye-blink procedure were the percentage of CRs, CR peak latency, CR amplitude, and UR amplitude. For each of these variables measured during the preshift session (i.e., Blocks 1-10 of paired CS-US trials), a repeated measures ANOVA was used to assess the between-subjects effect of ISI (2 levels) and the within-subjects effect of trial block (10 levels). The same analyses were conducted separately for the postshift session (i.e., Blocks 11-20). In order to compare the ISI shift effect across all groups during the second session, a 2 (short ISI, long ISI) x 2 (shift, no shift) x 10 (Blocks 11-20) repeated measures ANOVA was conducted. Finally, to assess potential differences in CR acquisition after an ISI shift, we calculated a shift cost, defined as the difference in the percentages of CRs between the last block of training with the first ISI (i.e., Block 10) and the first block of training with the second ISI (i.e., Block 11). ISI shift costs were compared using one-way ANOVAs. For the primary dependent variables - percentage of $\mathrm{CRs}$ and $\mathrm{CR}$ peak latency-effect sizes are reported $\left(\eta_{\mathrm{p}}{ }^{2}\right)$, where small effect sizes are less than .06 , moderate effect sizes range from .06 to .14 , and large effect sizes are greater than .14 (Cohen, 1973).

For the N100 and P200 components, peak amplitude and latency values were used as the dependent measures. The signals showed local maxima at the $\mathrm{FCz}$ electrode, and all statistical analyses were conducted on data from this site. Within each subject and for each condition, trial averages were computed for the first and second halves of the respective trial runs (i.e., Blocks $1-5$ and 6-10, respectively). This was done to examine possible associations between ERP amplitude/latency and conditioned learning across the acquisition phases of each session, while simultaneously ensuring a sufficient number of trials for adequate signal-to-noise ratios.

Pearson correlations were used to examine the relationship between tone-CS ERPs (N100 and P200 amplitude and 
latencies) and percentage of CRs, CR latency, and CR amplitude for each condition. All statistical tests had an alpha level of $p<.05$ to determine significance (two-tailed). If Mauchly's test of sphericity was significant, a Greenhouse-Geisser adjustment to the degrees of freedom was applied and the corresponding significance value reported. All tests were performed using the software package SPSS 14.0.

\section{Results}

Session 1 (Blocks 1-10)

Short versus long ISI In order to compare the difference in acquisition rates between the two ISIs, the percent CRs, CR peak latencies, CR amplitudes, and UR amplitudes during Session 1 (i.e., the 10 preshift blocks) were analyzed. As seen in Fig. 1a, a higher percentage of CRs were acquired in the short condition $(M=70.01 \% \pm 3.14 S D)$, as compared to the long condition $(62.62 \% \pm 3.14)$. A $2 \mathrm{x}$ 10 (Condition $\mathrm{x}$ Block) repeated measures ANOVA revealed a main effect of ISI for percent CRs, $F(1,54)=$ $4.79, p=.033, \eta_{\mathrm{p}}{ }^{2}=.08$, a main effect of block, $F(9,46)=$ 24.12, $p=.001, \eta_{\mathrm{p}}{ }^{2}=.30$, and an ISI x Block interaction, $F$ $(9,46)=3.38, p=.002, \eta_{\mathrm{p}}{ }^{2}=.057$. The main effect of block indicated that there was an increase in percent CRs from the early to the late trial blocks and the interaction indicated that the percentage of CRs increased more quickly in the short than in the long-ISI condition. As can be seen in Fig. 1b, the short-ISI condition yielded a mean peak latency closer to the US onset $(M=76.30 \mathrm{~ms} \pm 3.75$ $S D)$, relative to the long condition (111.09 $\mathrm{ms} \pm 3.75)$. For CR peak latency, there was a main effect of block, $F(9,46)$ $=6.95, p<.001, \eta_{\mathrm{p}}{ }^{2}=.110$, a main effect of ISI, $F(1,56)=$ $43.08, p<.001, \eta_{\mathrm{p}}{ }^{2}=.435$, and an ISI x Block interaction, $F(9,46)=2.32, p=.027, \eta_{\mathrm{p}}{ }^{2}=.040$. The ANOVA revealed that the peak latencies moved closer to US onset over the course of training and that the short ISI produced CR peak latencies closer to the US onset than did the longer ISI. The CR amplitudes for the short condition $(M=6.198 \pm$ $0.680 S D$ ) were larger than those for the long condition (3.939 \pm 0.692$)$. Accordingly, CR amplitude revealed a main effect of ISI, $F(1,55)=5.42, p=.024, \eta_{\mathrm{p}}{ }^{2}=.090$, as well as a main effect of block, $F(9,46)=2.75, p=.034$, $\eta_{\mathrm{p}}{ }^{2}=.048$, and an ISI $\mathrm{x}$ Block interaction, $F(9,46)=6.68$, $p<.001, \eta_{\mathrm{p}}{ }^{2}=.108$. UR amplitude showed a main effect of block, $F(9,46)=65.69, p<.001, \eta_{\mathrm{p}}^{2}=.540$, but no differences between ISI conditions. Overall, the short ISI exhibited a higher percentage of CRs, CR timings that were closer to the US onset, and larger CR amplitudes. Thus, conditioning was better for the short than for the long ISI.
Session 1 short ISI: Short-to-short versus short-to-long ISI The 10 preshift blocks of the short-to-short condition were compared to those from the short-to-long condition (see Fig. 2a) in order to rule out the possibility that performance in these two initial short-ISI conditions differed. A 2 (shift condition group) x 10 (blocks) repeated measures ANOVA was calculated for percent CRs, CR peak latencies, and CR amplitudes. As expected, a main effect of block was observed for percent CRs, $F(9,17)=24.62, p<$ $.001, \eta_{\mathrm{p}}{ }^{2}=.477, \mathrm{CR}$ latency, $F(9,17)=9.76, p<.001$, $\eta_{\mathrm{p}}^{2}=.265$, and CR amplitude, $F(9,17)=7.85, p<.001$, $\eta_{\mathrm{p}}{ }^{2}=.225$. Furthermore, there were no main effects of shift condition group, indicating that the rates of learning, the
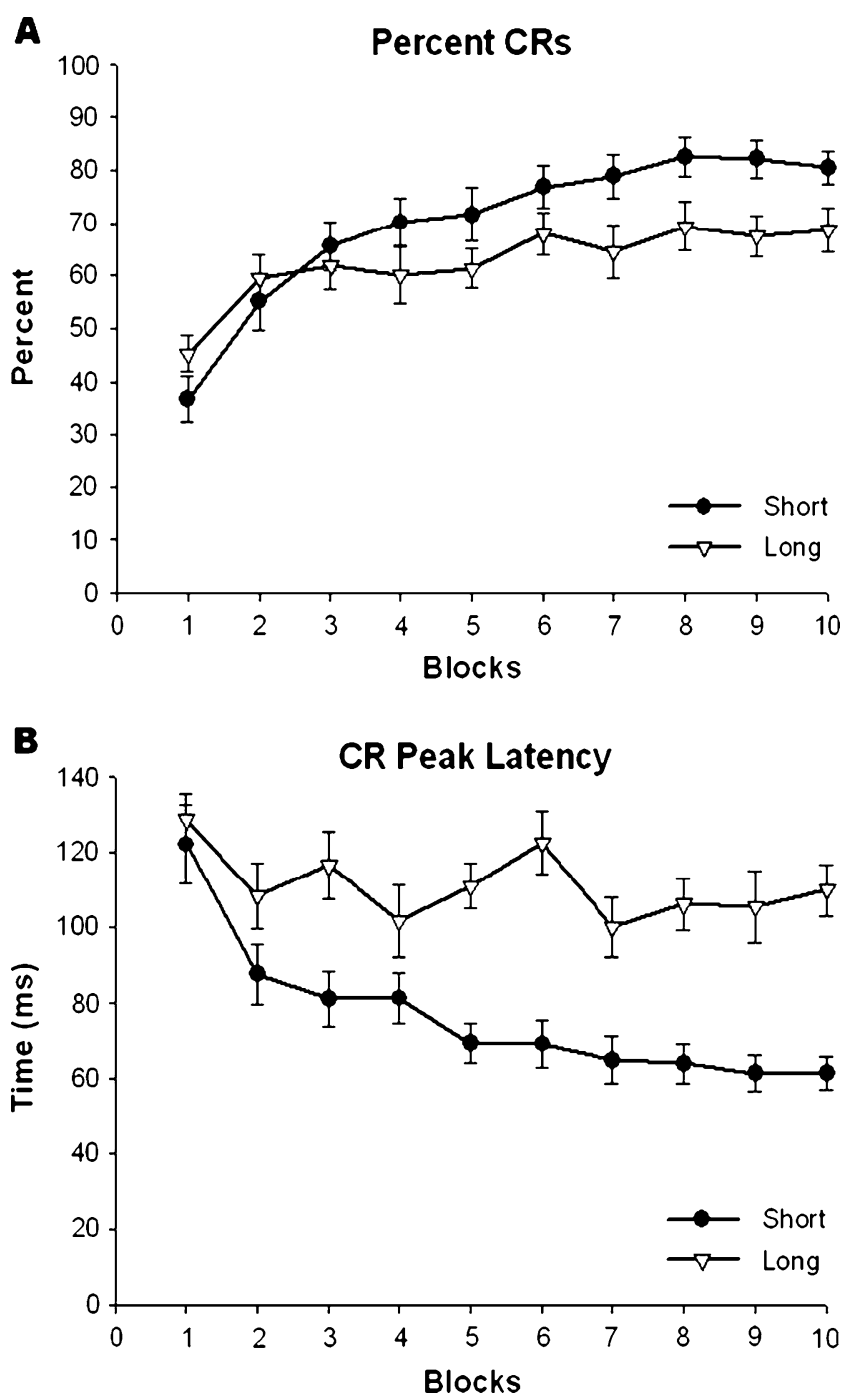

Fig. 1 (A) Percent CRs for Session 1 (Blocks 1-10) of the short (350$\mathrm{ms})$ and long (850-ms) ISIs. Learning of the conditioned response (CR) using the short CS produced a higher frequency of CRs than did using the long CS. (B) Peak latencies of the response were determined for both conditions. The US onset ( $350 \mathrm{~ms}$ for short; $850 \mathrm{~ms}$ for long) was subtracted in order to obtain the peak latencies. The short CS produced a more adaptive response that was closer to the US onset than was the response for the long CS. All error bars indicate SEMs 
timing of responses, and the amplitudes of the responses were similar between these groups that both began with a short-ISI session. No interactions were significant.

Session 1 long ISI: Long-to-short versus long-to-long ISI Figure $2 \mathrm{~b}$ depicts the percent CRs for the long-toshort and long-to-long conditions. The first 10 blocks of the long-to-short condition were compared to the same set of trial blocks in the long-to-long condition in order to rule out the possibility that performance in these two initial long-ISI conditions differed. A repeated measures ANOVA was conducted for percent CRs, CR peak latencies, and CR amplitudes. A main effect of block was observed for percent CRs, $F(9,19)=4.25, p<.001, \eta_{\mathrm{p}}^{2}=.136$. As expected, main effects of shift condition were not present
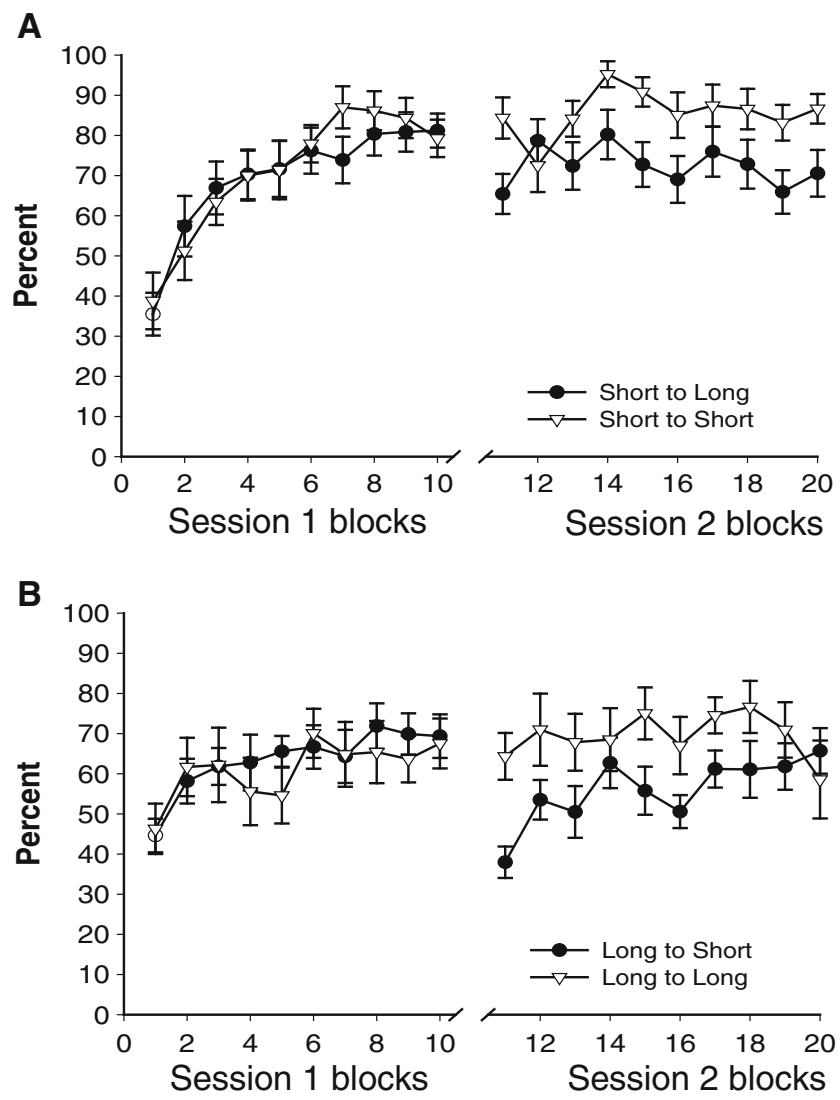

Fig. 2 Percentages of conditioned responses (CRs) across all conditioning blocks for each group. (a) Percent CRs for the 350- to $850-\mathrm{ms}$ ISI and $350-$ to $350-\mathrm{ms}$ ISI groups. Comparable rates of learning were observed for Session 1 (Blocks 1-10). A drop in percent CRs occurred for the 350- to 850-ms ISI at Block 11 after the shift. During Session 2 (Blocks 11-20), the 350- to 850-ms ISI group produced a mean of $72.38 \% \mathrm{CRs}$, and the 350 - to 350 -ms ISI group produced a mean of $85.6 \%$ CRs. (b) Percent CRs for the 850 - to 350 ms ISI and 850- to 850-ms ISI groups. Comparable rates of learning were observed for Session 1 (Blocks 1-10). A drop in CRs was observed in Block 11, followed by acquisition of the new ISI. The shift from the 850- to the 350-ms ISI had a large shift cost (Block $10-$ Block $11 ; M=-31.39$ ) as compared to the 350 - to $850-\mathrm{ms}$ ISI $(M=-15.77)$. All error bars indicate SEMs for $\mathrm{CR}$ latencies or $\mathrm{CR}$ amplitudes, nor was there a significant ISI $\mathrm{x}$ Shift interaction, indicating that the groups learned the response but didn't differ in their rates of learning or the timing of their CRs during the first 100 trials of preshift conditioning.

To summarize, the results indicated that, irrespective of ISI shift condition, the two groups of participants who initially learned the short ISI did not differ from each other on initial conditioning performance, nor did the two groups of subjects who learned the long ISI during the initial 10 trial blocks (i.e., before the possible shift).

Session 2 (Blocks 11-20)

Session 2 performance across all groups A 2 (short ISI, long ISI) x 2 (shift, no shift) x 10 (Blocks 11-20) repeated measures ANOVA was completed to compare Session 2 conditioning across all groups. For percent $\mathrm{CRs}$, main effects of block, $F(9,44)=3.602, p=.002, \eta_{\mathrm{p}}^{2}=.424$, and shift, $F(1,52)=9.155, p=.004, \eta_{\mathrm{p}}{ }^{2}=.150$, and an ISI $\mathrm{x}$ Shift interaction, $F(1,52)=13.962, p<.001, \eta_{\mathrm{p}}^{2}=.212$, were observed. Thus, the overall percent CRs for the short and long ISIs were attained at similar levels. However, the overall EBC was differentially affected by shifts versus continuations of the previous ISI, and the effect of shift was greater for the group shifted from the long as compared to the short ISI. No main effects or interactions were observed in regard to $\mathrm{CR}$ peak latencies or amplitudes.

Session 2 short-to-long versus short-to-short comparisons Percent CRs, CR peak latencies, and CR amplitudes were compared for Session 2 of the short-to-long condition versus Session 2 of the short-to-short condition, thus comparing the long and short ISIs at Session 2 in the two groups that had received the short ISI in Session 1. For percent CRs, a repeated measures ANOVA revealed a main effect of ISI, $F(1,27)=4.23 p=.050, \eta_{\mathrm{p}}^{2}=.135$, with the short ISI producing a higher number of percent CRs $(M=$ $85.6 \% \pm 5.06)$ as compared to the long ISI $(72.38 \% \pm$ 3.96). In order to compare CR peak latencies between the groups, the onset of the US was subtracted from the peak value $(850 \mathrm{~ms}$ for the long ISI and $350 \mathrm{~ms}$ for the short ISI). The short-to-long group ( $M=109.64 \mathrm{~ms} \pm 4.67)$ had significantly later peaks than did the short-to-short group (60.044 $\mathrm{ms} \pm 5.98)$. CR peak latency revealed a main effect of group, $F(1,27)=42.71, p<.001, \eta_{\mathrm{p}}{ }^{2}=.613$. CR amplitude revealed a main effect of block, $F(9,17)=7.85$, $p=.001, \eta_{\mathrm{p}}{ }^{2}=.225$. No significant interactions emerged.

To summarize, the short-to-short and short-to-long groups showed identical initial learning, as described in the previous Results section for Session 1. However, when the ISI was shifted in the short-to-long group, there was a 
decrease in CR production and a shift in the peak latency toward US onset, as compared to the group that continued with the short ISI. In the group that shifted from the short to the long ISI, the CRs shifted to a later point in time, as expected, but they were still earlier relative to US onset than were CRs in the group that stayed at the short ISI.

Session 2 short-to-long versus long-to-long comparisons In order to compare the effects of the ISI shift, EBC performance in Session 2 of the short-to-long condition was compared to performance in Session 2 of the long-to-long condition; thus, while long-ISI performance was examined in both groups, one group had initially been trained on a short ISI (shift group), whereas the other was initially trained on a long ISI (nonshift group). The raw EMGs for the long ISI in the short-to-long condition can be seen in Fig. 3. During the first part of the shift, a double blink response can be seen that occurs close to the onset of the US preshift. This double blink response is lost over the course of training to the new, long ISI. A 2 (condition) x 10 (block) repeated measures ANOVA was completed for percent CRs, CR peak latencies, and CR amplitudes. For percent CRs, a repeated measures ANOVA revealed no main effect of block $(p=.26)$ or of shift condition $(p=.66)$. No significant interactions were observed. The groups that had received the long condition in Session 1 had a mean percentage of CRs of $69.43( \pm 5.76)$, as compared to the group that went from short to long, which had a mean percent CR of $72.38( \pm 4.14)$. There were no group differences for CR peak latencies and amplitudes, nor were there any significant interactions. These data indicate that the long ISI in the short-to-long condition was learned to a level similar to the one seen in the group that received 100 trials of previous exposure to the long ISI.

Session 2 long-to-short versus long-to-long comparisons Percent CRs, CR peak latencies, and CR amplitudes were compared for Session 2 for the long-to-short versus the longto-long condition. For percent $\mathrm{CRs}$, the long-to-long condition had a significantly higher number of CRs $(M=69.43 \pm 3.97)$ relative to the long-to-short condition $(56.07 \pm 3.10)$, as indicated by a main effect of ISI, $F(1,27)=7.026, p=.013$, $\eta_{\mathrm{p}}{ }^{2}=.206$. The long-to-short group $(M=72.83 \mathrm{~ms} \pm 6.14)$ had significantly earlier $\mathrm{CR}$ peak latencies than the long-tolong group (104.20 $\mathrm{ms} \pm 7.85)$, as indicated by a main effect of ISI, $F(1,27)=9.91, p=.004, \eta_{\mathrm{p}}{ }^{2}=.268$. For CR peak latencies, there was also a Block $\mathrm{x}$ Condition interaction, $F(9,19)=3.17, p=.016, \eta_{\mathrm{p}}{ }^{2}=.600$. There were no group differences in regard to CR amplitudes, and none of the interactions reached significance.

To summarize, the long-to-long and long-to-short groups showed identical initial learning of the long ISI, as described in the previous Results section for Session 1. However, the groups differed in their percentages of conditioning after the
ISI shift (i.e., during Session 2), with the long-to-long group having a higher percentage of conditioned responses in comparison to the long-to-short group, which experienced an ISI shift. Thus, the shift from long to short impaired conditioning to the short ISI. However, the timing of the responses was closer to the US onset for the long-to-short condition than for the long-to-long condition.

Session 2 long-to-short versus short-to-short comparisons To compare the effects of the shift, Session 2 of the long-to-short ISI condition was compared to Session 2 of the short-to-short ISI condition. A 2 (condition) x 10 (block) repeated measures ANOVA was completed for percent CRs, CR peak latencies, and CR amplitudes. For percent CRs, a repeated measures ANOVA revealed a main effect of block, $F(9,27)=2.86, p=$ $.03, \eta_{\mathrm{p}}{ }^{2}=0.602$, and a main effect of shift, $F(1,25)=33.535$, $p<.001, \eta_{\mathrm{p}}{ }^{2}=.573$, but no interaction was observed. The groups that received the short condition first had a greater number of CRs $(M=85.60 \% \pm 4.55)$ than did the group that went from long to short $(56.07 \% \pm 3.86)$. There were no group differences or interactions in regard to CR amplitudes or peak latencies. When shifting from long to short, the percentage of CRs was lower than in the conditions in which short had been given first. Thus, the long condition impaired subsequent performance during the short condition.

Shift cost A one-way ANOVA compared the shift costs of the short-to-long and short-to-short ISI conditions, revealing a main effect of shift cost, $F(1,27)=6.057, p=.021$, with the shift cost from the short to the long ISI $(M=$ $15.77 \% \pm 5.72$ ) being significantly greater than that from the short to the short ISI $(-5.06 \% \pm 5.37)$. An ANOVA comparing the long-to-short group to the long-to-long group revealed a main effect of shift cost, $F(1,27)=$ 7.544, $p=.011$, with the shift cost being significantly smaller from the short to the long ISI $(M=31.39 \% \pm 7.47)$ than from the long to the long ISI $(3.22 \% \pm 4.61)$. Finally, the short-to-long ISI condition was compared to the longto-short ISI condition. While there was no main effect of shift cost, $F(1,34)=2.759, p=.106$, the group with a short-tolong ISI shift $(M=15.77 \% \pm 5.72)$ exhibited a smaller difference than did the group with a long-to-short ISI shift $(M=31.39 \% \pm 7.47)$. Both shift conditions had significantly larger drops in percentages of CRs than did the nonshifted conditions, indicating that the decrease was due to the shift in ISI and not to the brief rest break between the sessions.

\section{EEG results}

Figure 4 illustrates representative ERPs to the tone CS during EBC acquisition for the 350- to $850-\mathrm{ms}$ shift condition. As can be seen in the figure, a robust N100- 


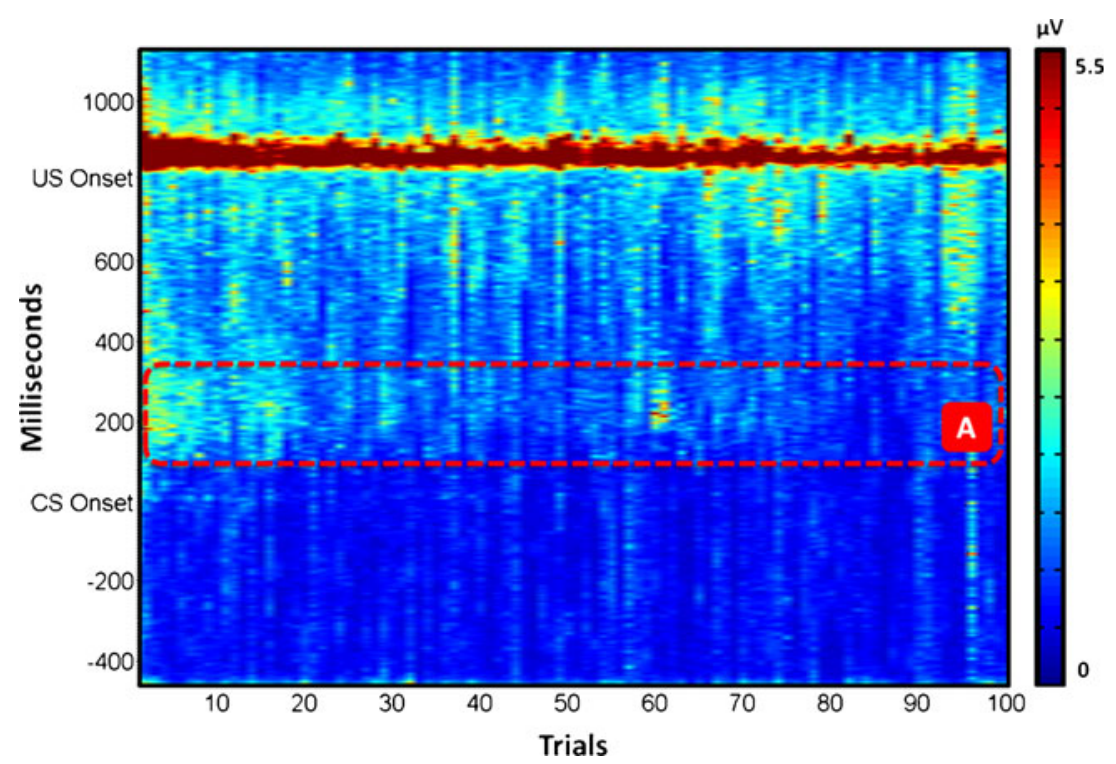

Fig. 3 Grand average trial-by-trial EMG data for all paired CS-US trials for Session 2 (i.e., postshift) in the short-to-long group. Thus, shown here are the postshift behavioral data for the group that was initially trained on the short ISI. In the present depiction of the longISI responses, the $900-\mathrm{ms}$ tone $\mathrm{CS}(1 \mathrm{kHz}, 80 \mathrm{~dB})$ coterminated with a 50-ms (10-psi) air puff. The outlined section (A) displays the time window in which conditioned responses (CRs) were counted for the short conditioning (100-350 ms post-CS-onset). It can be seen that these participants, who were initially trained at the short ISI, continued

P200 complex was reliably elicited to CS onset. This response was similarly observed in the other three shift conditions (data not shown). Pearson correlations revealed that neither N100 nor P200 measures (i.e., amplitude and latency) correlated with percent $\mathrm{CR}, \mathrm{CR}$ latency, $\mathrm{CR}$ amplitude, CR shift cost, or UR variables during EBC acquisition for any of the EBC conditions.

\section{Discussion}

Participants were initially trained in an eye-blink conditioning session using either a short (350-ms) or long (850-ms) ISI. Immediately following initial training, a second EBC session occurred using either the same ISI (i.e., no shift) or a different ISI (i.e., shift). The short ISI produced higher rates of conditioned response and CR latencies that were closer to the US as compared to the long-ISI condition, thus indicating that the short ISI was more optimal for learning. Overall, there was a significant effect of the ISI shift on the percentage of CRs, irrespective of the direction (i.e., short to long or long to short). However, the shift from the optimal short ISI to the nonoptimal long one resulted in a smaller shift cost than when the shift was from the long to the short ISI.

Previous studies examining multiple ISI durations found that the optimal ISI lies approximately between 200 and to exhibit blink activity early in this long-ISI session (e.g., up through at least Trial 20) at the point in time (100-350 ms post-CS) where they were initially trained to produce CRs. However, by approximately Trial 30, the participants had begun to extinguish these early, previously adaptive responses and establish a more consistent response pattern in the new, 600- to $850-\mathrm{ms} \mathrm{CR}$ window. By the latter blocks of training (i.e., Trials $65-100$ ), EMG blink activity is highly concentrated in the period immediately preceding the US, where it had been largely absent in the earlier period

$500 \mathrm{~ms}$ in both nonhuman mammals (Coleman \& Gormezano, 1971; Gormezano et al., 1962; Schneiderman, 1966; Schneiderman \& Gormezano, 1964; Smith, 1968; Smith, Coleman, \& Gormezano, 1969) and humans (McAllister, 1953). Accordingly, in the present study the short ISI (350 ms) was within an optimal range, whereas the long ISI $(850 \mathrm{~ms})$ was not. As expected, the short ISI produced a higher percentage of CRs and better timing of the responses than did the long ISI. In addition, the short ISI produced CR onsets and peak latencies that were closer to the US onset. These later onsets provided another indication that the short ISI is more optimal for learning. In addition, the long-to-short ISI shift produced timing closer to the US after the shift, as compared to the secondsession results of the long-to-long group. Even though the long-to-long group already had 100 trials of training in the initial long learning phase, their timing was further from the US in the second long phase, in contrast to the group that was shifted to the short ISI. This indicates that the short ISI produced better timing relative to the US than did the long ISI, and this result is consistent with conclusions from prior studies that the 200- to 500-ms CS range produces optimal conditioning in humans, as compared to ISIs that fall outside of this range (McAllister, 1953).

After shifting to the long ISI from initial training with the short ISI, a double peak response was observed (Fig. 3); 


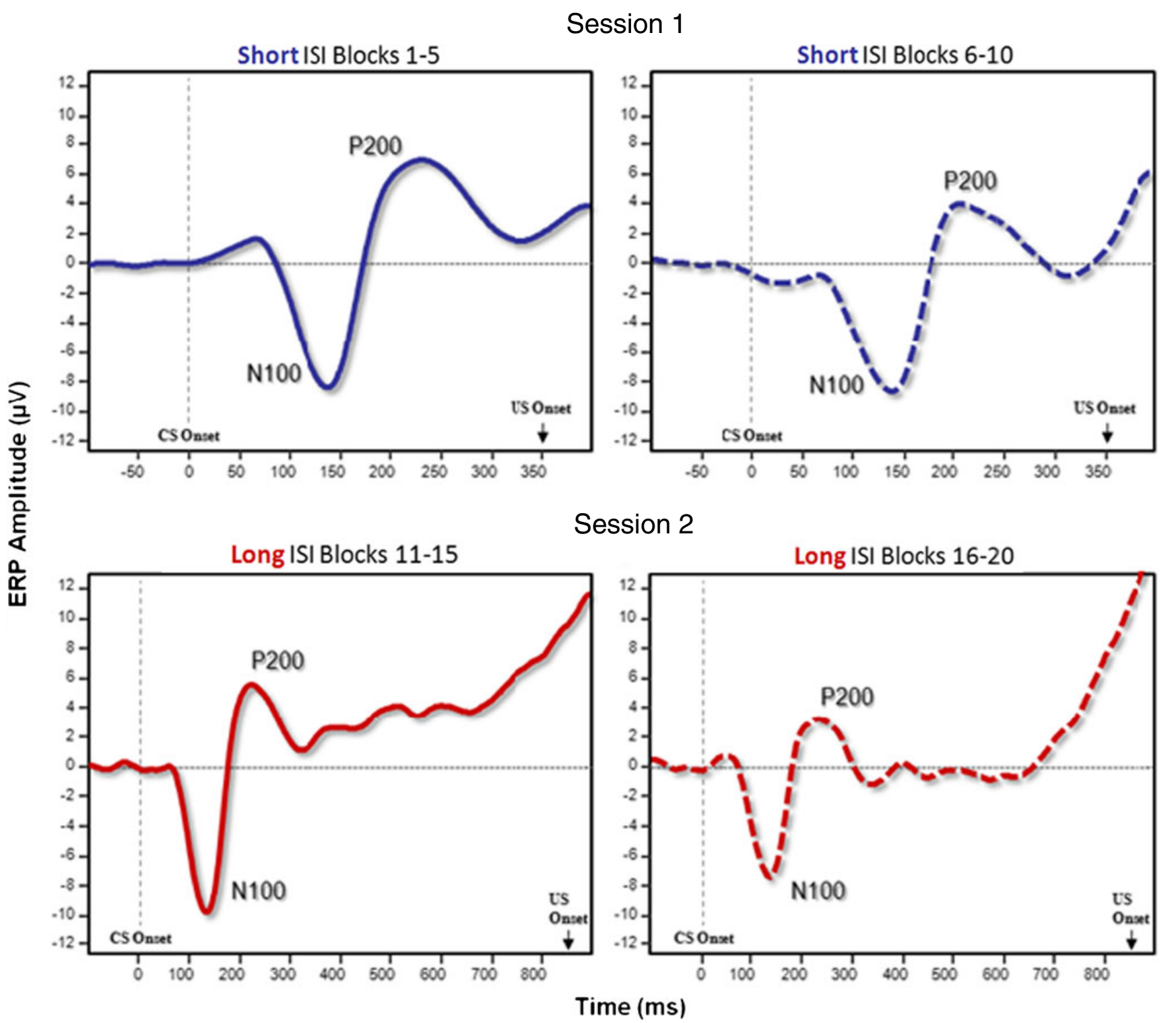

Fig. 4 As can be seen in the figure, a robust N100-P200 complex was reliably elicited across the runs subsequent to CS onset in the short-to-long ISI group. This response was similarly observed in the

the first peak was closely associated with the training that occurred at the first ISI (near $200 \mathrm{~ms}$ after CS onset), and the second peak occurred during the second ISI (near $800 \mathrm{~ms}$ after CS onset). The blink response timed to the initial ISI duration diminished over training, while the later blink response was refined, thus suggesting that the first ISI response was extinguished while the second ISI was learned. When the ISI was shifted from the short to the long ISI (i.e., from optimal to nonoptimal), the CRs were acquired more rapidly than when shifted in the other direction. Similar trends have been reported by others who have studied the ISI switch in both humans (Boneau, 1958; Ebel \& Prokasy, 1963; McAllister, 1953; Prokasy, other three shift conditions (figures not shown). Pearson correlations revealed no significant correlations between the sensory ERPs and measures of conditioned learning

Ebel, \& Thompson, 1963) and nonhuman mammals (Coleman \& Gormezano, 1971; Leonard \& Theios, 1967; Prokasy \& Papsdorf, 1965). The present study found that when shifting from the long to the short ISI, the short-ISI conditioning blocks were impaired relative to other short conditions. The short-to-long shift produced normal acquisition, although the mean percent CRs were higher than those for the groups given initial training to the long ISI. In comparison, initial learning to the long ISI impaired conditioning to the short ISI.

In terms of the brain ERP results, neither the N100 nor the P200 amplitude and latency to the tone CS correlated with percentages of CRs, CR latencies, or CR amplitudes, 
or shift costs. This lack of an association between CSevoked ERPs and measures of learning is in accordance with animal work on CS processing. It is well established that the lateral pontine nucleus represents the primary projection system for CS input into the cerebellum (Bao, Chen, \& Thompson, 2000; Freeman \& Rabinak, 2004; Freeman, Rabinak, \& Campolattaro, 2005; Gould, Sears, \& Steinmetz, 1993; Hesslow, Svensson, \& Ivarsson, 1999; Knowlton \& Thompson, 1988; Lewis, LoTurco, \& Solomon, 1987; Steinmetz, 1990b; Steinmetz, Lavond, \& Thompson, 1989; Steinmetz et al., 1987; Steinmetz, Rosen, Chapman, Lavond, \& Thompson, 1986; Steinmetz \& Sengelaub, 1992; Tracy, Thompson, Krupa, \& Thompson, 1998). While there are projections from auditory cortices to the pontine (Knowlton et al., 1993), it appears that an intact auditory cortex is not necessary for conditioning to occur (Knowlton \& Thompson, 1992; Oakley \& Russell, 1977). Instead, the data suggest that the primary pathways of CS entry into the pontine nuclei originate from the cochlear nuclei (Campolattaro et al., 2007; Gould et al., 1993; Steinmetz et al., 1987), inferior colliculus (Freeman et al., 2007), and medial auditory thalamus (Campolattaro et al., 2007). While these ideas are speculative, the lack of N100 and P200 learning-related associations could reflect the possibility that auditory cortex is not necessary for normal $\mathrm{CR}$ acquisition in humans. However, it should be noted that several functional imaging studies in humans have in fact shown auditory cortical activity for paired trials during EBC (Molchan, Sunderland, McIntosh, Herscovitch, \& Schreurs, 1994; Schreurs et al., 1997; but see Ramnani, Toni, Josephs, Ashburner, \& Passingham, 2000, for an exception). Further work will be necessary to determine the specific role (if any) of the sensory cortex during delay $\mathrm{EBC}$ in humans.

Several potential limitations should be mentioned. First, the present procedure involved shifts from a nonoptimal (850$\mathrm{ms})$ to an optimal (350-ms) ISI, and vice versa. Whether the same pattern of results would be observed if the nonoptimal ISI were shorter (i.e., $200 \mathrm{~ms}$ ) than the optimal ISI is unclear. Second, it is possible that the short break taken before the shift (to reduce participant fatigue) adversely affected learning of the postshift CS ISI. However, all participants, even those who did not shift ISIs, received this break before starting the second half of conditioning. Thus, any potential confound was present across all shift conditions. It is also possible that the brief break may have had different effects on the groups wherein the same ISI was continued versus those wherein the ISI was shifted. Finally, in the present study, only paired CSUS trials were administered. Therefore, CR timing measures (e.g., onset and peak latencies) were taken during a $250-\mathrm{ms}$ window preceding US onset and may not reflect the complete $\mathrm{CR}$, if CR activity extended into the US presentation and response period. The addition of CS-alone trials would have precluded this potential problem; however, in human EBC studies-where $10 \%$ of trials may be CS-alone trials (e.g., Steinmetz, Edwards, Steinmetz, \& Hetrick, 2009) - it is not practical to extend the duration of training long enough to obtain a sufficient number of CS-alone trials for meaningful analyses, because of problems with fatigue, eye irritation, and compliance. Also, the 250-ms CR window may have precluded the measurement of CRs that occurred earlier in the ISI for the $750-\mathrm{ms}$ CS. However, analysis of the $250-\mathrm{ms}$ window versus a longer $750-\mathrm{ms}$ window revealed no significant differences in CRs. Thus, the $250-\mathrm{ms}$ window was chosen in order to examine more clearly the effects of the ISI shift.

Previous research using a single-cue delay EBC paradigm found deficits in clinical groups with conditions including schizophrenia (Bolbecker, Mehta, Edwards, et al., 2009; Brown et al., 2005), bipolar disorder (Bolbecker, Mehta, Johannesen, et al., 2009), and drug abuse (Skosnik et al., 2007). However, few studies involving the CS-US ISI have been completed, and none involving clinical groups. Revisiting and extending the human ISI shift literature furthers our understanding of the acquisition and timing of blink responses after an ISI shift and will facilitate the application of this procedure in clinical studies. The finding that learning was better (i.e., higher percentages of CRs and better timing) when shifting from a 350- to an 850-ms ISI in comparison to from an 850- to a $350-\mathrm{ms}$ ISI suggests that learning an optimal ISI enhances subsequent conditioning to a nonoptimal ISI. Like the traditional single-duration delay EBC task, performance in the present ISI shift task was hypothesized to reflect the functional integrity of the cerebellar cortex and deep nuclei. Moreover, the ability to assess shift costs in the ISI shift procedure may provide a more sensitive measure of cerebellar mechanisms of timing. Increased sensitivity to cerebellar functions may be highly valuable in studies of clinical samples with putative cerebellar abnormalities.

\section{References}

Attwell, P. J., Rahman, S., \& Yeo, C. H. (2001). Acquisition of eyeblink conditioning is critically dependent on normal function in cerebellar cortical lobule HVI. Journal of Neuroscience, 21, 5715-5722.

Bao, S., Chen, L., \& Thompson, R. F. (2000). Learning- and cerebellum-dependent neuronal activity in the lateral pontine nucleus. Behavioral Neuroscience, 114, 254-261.

Blaxton, T. A., Zeffiro, T. A., Gabrieli, J. D. E., Bookheimer, S. Y., Carrillo, M. C., Theodore, W. H., et al. (1996). Functional mapping of human learning: A positron emission tomography activation study of eyeblink conditioning. Journal of Neuroscience, 16, 4032-4040.

Bolbecker, A. R., Mehta, C., Edwards, C. R., Steinmetz, J. E., O’Donnell, B. F., \& Hetrick, W. P. (2009). Eye-blink conditioning deficits indicate temporal processing abnormalities in schizophrenia. Schizophrenia Research, 111, 182-191. 
Bolbecker, A. R., Mehta, C., Johannesen, J. K., Edwards, C. R., O'Donnell, B. F., Shekhar, A., et al. (2009). Eyeblink conditioning anomalies in bipolar disorder suggest cerebellar dysfunction. Bipolar Disorders, 11, 19-32.

Boneau, C. A. (1958). The interstimulus interval and the latency of the conditioned eyelid response. Journal of Experimental Psychology, 56, 464-471.

Boneau, C. A., King, R. A., \& Kimble, G. A. (1956). The effect of changing the interstimulus interval on the acquisition of the conditioned eyelid response. American Psychology, 11, 393.

Brown, S. M., Keiffaber, P. D., Carroll, C. A., Vohs, J. L., Tracy, J. A., Shekhan, A., et al. (2005). Eyeblink conditioning deficits indicate timing and cerebellar abnormalities in schizophrenia. Brain and Cognition, 58, 94-108.

Campolattaro, M. M., Halverson, H. E., \& Freeman, J. H. (2007). Medial auditory thalamic stimulation as a conditioned stimulus for eyeblink conditioning in rats. Learning and Memory, 14, $152-159$.

Chen, L., Bao, S., Lockard, J. M., Kim, J. K., \& Thompson, R. F. (1996). Impaired classical eyeblink conditioning in cerebellarlesioned and Purkinje cell degeneration (PCD) mutant mice. Journal of Neuroscience, 16, 2829-2838.

Chen, L., Bao, S., \& Thompson, R. F. (1999). Bilateral lesions of the interpositus nucleus completely prevent eyeblink conditioning in Purkinje cell-degeneration mutant mice. Behavioral Neuroscience, 113, 204-210.

Christian, K. M., \& Thompson, R. F. (2003). Neural substrates of eyeblink conditioning: Acquisition and retention. Learning and Memory, 10, 427-455.

Cohen, J. (1973). Eta-squared and partial eta-squared in fixed factor ANOVA designs. Educational and Psychological Measurement, 33, 107-112. doi:10.1177/001316447303300111.

Coleman, S. R., \& Gormezano, I. (1971). Classical conditioning of the rabbit's (Oryctolagus cuniculus) nictitating membrane response under symmetrical CS-US interval shifts. Journal of Comparative Physiology and Psychology, 77, 447-455.

Coull, J. T. (1998). Neural correlates of attention and arousal: Insights from electrophysiology, functional neuroimaging and psychopharmacology. Progress in Neurobiology, 55, 343-361.

Daum, I., Schugens, M. M., Ackermann, H., Lutzenberger, W., Dichgans, J., \& Birbaumer, N. (1993). Classical conditioning after cerebellar lesions in humans. Behavioral Neuroscience, 107, 748-756.

Dimitrova, A., Weber, J., Redies, C., Kindsvater, K., Maschke, M., Kolb, F. P., et al. (2002). MRI atlas of the human cerebellar nuclei. NeuroImage, 17, 240-255.

Ebel, H. C., \& Prokasy, W. F. (1963). Classical eyelid conditioning as a function of sustained and shifted interstimulus intervals. Journal of Experimental Psychology, 65, 52-58.

Edwards, C. R., Skosnik, P. D., Steinmetz, A. B., Vollmer, J. M., O'Donnell, B. F., \& Hetrick, W. P. (2008). Assessment of forebrain-dependent trace eyeblink conditioning in chronic cannabis users. Neuroscience Letters, 439, 264-268.

Finkbiner, R. G., \& Woodruff-Pak, D. S. (1991). Classical eyeblink conditioning in adulthood: Effects of age and interstimulus interval on acquisition in the trace paradigm. Psychology and Aging, 6, 109-117.

Freeman, J. H., \& Rabinak, C. A. (2004). Eyeblink conditioning in rats using pontine stimulation as a conditioned stimulus. Integrative Physiological and Behavioral Science, 39, 180-191.

Freeman, J. H., Rabinak, C. A., \& Campolattaro, M. M. (2005). Pontine stimulation overcomes developmental limitations in the neural mechanisms of eyeblink conditioning. Learning and Memory, 12, 255-259.

Freeman, J. H., Halverson, H. E., \& Hubbard, E. M. (2007). Inferior colliculus lesions impair eyeblink conditioning in rats. Learning and Memory, 14, 842-846.
Garcia, K. S., Steele, P. M., \& Mauk, M. D. (1999). Cerebellar cortex lesions prevent acquisition of conditioned eyelid responses. Journal of Neuroscience, 19, 10940-10947.

Gerwig, M., Hajjar, K., Dimitrova, A., Maschke, M., Kolb, F. P., Frings, M., et al. (2005). Timing of conditioned eyeblink responses is impaired in cerebellar patients. Journal of Neuroscience, 25, 3919-3931.

Gerwig, M., Kolb, F. P., \& Timmann, D. (2007). The involvement of the human cerebellum in eyeblink conditioning. Cerebellum, 6 , $38-57$.

Gormezano, I., Schneiderman, N., Deaux, E., \& Fuentes, I. (1962). Nictitating membrane: Classical conditioning and extinction in the albino rabbit. Science, 138, 33-34.

Gould, T. J., Sears, L. L., \& Steinmetz, J. E. (1993). Possible CS and US pathways for rabbit classical eyelid conditioning: Electrophysiological evidence for projections from the pontine nuclei and inferior olive to cerebellar cortex and nuclei. Behavioral Neural Biology, 60, 172-185.

Gratton, G., Coles, M. G., \& Donchin, E. (1983). A new method for off-line removal of ocular artifact. Electroencephalography and Clinical Neurophysiology, 55, 468-484.

Hesslow, G., Svensson, P., \& Ivarsson, M. (1999). Learned movements elicited by direct stimulation of cerebellar mossy fiber afferents. Neuron, 24, 179-185.

Hillyard, S. A., Hink, R. F., Schwent, V. L., \& Picton, T. W. (1973). Electrical signs of selective attention in the human brain. Science, 182, 177-180.

Knowlton, B. J., Thompson, J. K., \& Thompson, R. F. (1993). Projections from the auditory cortex to the pontine nuclei in the rabbit. Behavioural Brain Research, 56, 23-30.

Knowlton, B. J., \& Thompson, R. F. (1988). Microinjections of local anesthetic into the pontine nuclei reduce the amplitude of the classically conditioned eyelid response. Physiology and Behavior, 43, 855-857.

Knowlton, B. J., \& Thompson, R. F. (1992). Conditioning using a cerebral cortical conditioned stimulus is dependent on the cerebellum and brain stem circuitry. Behavioral Neuroscience, 106, 509-517.

Kraus, N., \& Disterhoft, J. (1982). Response plasticity of neurons in rabbit association cortex during tone signalled learning. Brain Research, 246, 205-215.

Lang, P. J., \& Greenwald, M. K. (1988). The International Affective Picture System standardization procedure and initial group results for affective judgments (Tech. Rep. 1A). Gainesville, FL: University of Florida, Center for Research in Psychophysiology.

Lavond, D. G., \& Steinmetz, J. E. (1989). Acquisition of classical conditioning without cerebellar cortex. Behavioural Brain Research, 33, 113-164.

Leonard, D. W., \& Theios, J. (1967). Effect of CS-US interval shift on classical conditioning of the nictitating membrane in the rabbit. Journal of Comparative Physiology and Psychology, 63, 355358.

Lewis, J. L., LoTurco, J. J., \& Solomon, P. R. (1987). Lesions of the middle cerebellar peduncle disrupt acquisition and retention of the rabbit's classically conditioned nictitating membrane response. Behavioral Neuroscience, 101, 151-157.

Logan, C. (1991). Cerebellar cortical involvement in excitatory and inhibitory classical conditioning. Palo Alto: Stanford University Press.

Logan, C. G., \& Grafton, S. T. (1995). Functional anatomy of human eyeblink conditioning determined with regional cerebral glucose metabolism and positron-emission tomography. Proceedings of the National Academy of Sciences, 92, 7500-7504.

Lye, R. H., O’Boyle, D. J., Ramsden, R. T., \& Schady, W. (1988). Effects of a unilateral cerebellar lesion on the acquisition of eyeblink conditioning in man. Journal of Physiology, 403, 58P. 
McAllister, W. A. (1953). Eyelid conditioning as a function of the CS-US interval. Journal of Experimental Psychology, 45, 417-422.

McCormick, D. A., \& Thompson, R. F. (1984). Cerebellum: Essential involvement in the classically conditioned eyelid response. Science, 223, 296-299.

McGlinchey-Berroth, R., Cermak, L. S., Carrillo, M. C., Armfield, S., Gabrieli, J. D. E., \& Disterhoft, J. F. (1995). Impaired delay eyeblink conditioning in amnesic Korsakoff's patients and recovered alcoholics. Alcohol Clinical Experimental Research, 19, 1127-1132.

Molchan, S. E., Sunderland, T., McIntosh, A. R., Herscovitch, P., \& Schreurs, B. G. (1994). A functional anatomical study of associative learning in humans. Proceedings of the National Academy of Sciences, 191, 122-126.

Nolan, B. C., \& Freeman, J. H. (2006). Purkinje cell loss by OX7saporin impairs acquisition and extinction of eyeblink conditioning. Learning and Memory, 13, 359-365.

Oakley, D. A., \& Russell, I. S. (1977). Subcortical storage of Pavlovian conditioning in the rabbit. Physiology and Behavior, 18, 931-937.

Perrett, S. P., Ruiz, B. P., \& Mauk, M. D. (1993). Cerebellar cortex lesions disrupt learning-dependent timing of conditioned eyelid responses. Journal of Neuroscience, 13, 1708-1718.

Poulos, A. M., \& Thompson, R. F. (2004). Timing of conditioned responses utilizing electrical stimulation in the region of the interpositus nucleus as a CS. Integrative Physiological and Behavioral Science, 39, 83-94.

Prokasy, W. F., Ebel, H. C., \& Thompson, D. D. (1963). Response shaping at long interstimulus intervals in classical eyelid conditioning. Journal of Experimental Psychology, 66, 138141. doi: $10.1037 / \mathrm{h} 0049246$.

Prokasy, W. F., \& Papsdorf, J. D. (1965). Effects of increasing the interstimulus interval during classical conditioning of the albino rabbit. Journal of Comparative and Physiological Psychology, 60, 249-252. doi:10.1037/h0022341.

Ramnani, N., Toni, I., Josephs, O., Ashburner, J., \& Passingham, R. F. (1999). Learning-related plasticity during human classical eyeblink conditioning: Whole-brain, event related fMRI. NeuroImage, 9, S980.

Ramnani, N., Toni, I., Josephs, O., Ashburner, J., \& Passingham, R. E. (2000). Learning- and expectation-related changes in the human brain during motor learning. Journal of Neurophysiology, 84, 3026-3035.

Rogers, R. F., Britton, G. B., \& Steinmetz, J. E. (2001). Learning-related interpositus activity is conserved across species as studied during eyeblink conditioning in the rat. Brain Research, 905, 171-177.

Schneiderman, N. (1966). Interstimulus interval function of the nictitating membrane response of the rabbit under delay versus trace conditioning. Journal of Comparative and Physiological Psychology, 62, 397-402.

Schneiderman, N., \& Gormezano, I. (1964). Conditioning of the nictitating membrane of the rabbit as a function of the CS-US interval. Journal of Comparative and Physiological Psychology, 57, 188-195.

Schreurs, B. G., McIntosh, A. R., Bahro, M., Herscovitch, P., Sunderland, T., \& Molchan, S. E. (1997). Lateralization and behavioral correlation of changes in regional cerebral blood flow with classical conditioning of the human eyeblink response. Journal of Neurophysiology, 77, 2153-2163.

Schugens, M. M., Topka, H. R., \& Daum, I. (2000). Eyeblink conditioning in neurological patients with motor impairments. In D. S. Woodruff-Pak \& J. E. Steinmetz (Eds.), Eyeblink classical conditioning: Applications in humans (Vol. 1, pp. 191-204). Boston: Kluwer.

Sears, L. L., Finn, P. R., \& Steinmetz, J. E. (1994). Abnormal classical eye-blink conditioning in autism. Journal of Autism and Developmental Disorders, 24, 737-751.
Skosnik, P. D., Edwards, C. R., O’Donnell, B. F., Steinmetz, J. E., Steffen, A., \& Hetrick, W. P. (2007). Cannabis use disrupts eyeblink conditioning: Evidence for cannabinoid modulation of cerebellardependent learning. Neuropsychopharmacology, 33, 1432-1440.

Smith, M. C. (1968). CS-US interval and US intensity in classical conditioning of the rabbit's nictitating membrane response. Journal of Comparative and Physiological Psychology, 66, 679-687.

Smith, M. C., Coleman, S. R., \& Gormezano, I. (1969). Classical conditioning of the rabbit's nictitating membrane response at backward, simultaneous and forward CS-US intervals. Journal of Comparative and Physiological Psychology, 69, 226-231.

Solomon, P. R., Stowe, G. T., \& Pendlbeury, W. W. (1989). Disrupted eyelid conditioning in a patient with damage to cerebellar afferents. Behavioral Neuroscience, 103, 898-902.

Spence, K. W., \& Ross, L. E. (1959). A methodological study of the form and latency of eyelid responses in conditioning. Journal of Experimental Psychology, 58, 376-381.

Steinmetz, J. E. (1990a). Classical nictitating membrane conditioning in rabbits with varying interstimulus intervals and direct activation of cerebellar mossy fibers as the CS. Behavioural Brain Research, 38, 97-108.

Steinmetz, J. E. (1990b). Neuronal activity in the rabbit interpositus nucleus during classical NM-conditioning with a pontinenucleus-stimulation CS. Psychological Science, 1, 378-382.

Steinmetz, J. E. (2000). Brain substrates of classical eyeblink conditioning: A highly localized but also distributed system. Behavioural Brain Research, 110, 13-24.

Steinmetz, A. B., Edwards, C. R., Steinmetz, J. E., \& Hetrick, W. P. (2009). Comparison of auditory and visual conditioning stimuli in delay eyeblink conditioning in healthy young adults. Learning \& Behavior, 37, 349-356.

Steinmetz, A. B., \& Freeman, J. H. (2010). Central cannabinoid receptors modulate acquisition of eyeblink conditioning. Learning and Memory, 17, 571-576.

Steinmetz, J. E., Lavond, D. G., \& Thompson, R. F. (1989). Classical conditioning in rabbits using pontine nucleus stimulation as a conditioned stimulus and inferior olive stimulation as an unconditioned stimulus. Synapse, 3, 225-233.

Steinmetz, J. E., Logan, C. G., Rosen, D. J., Thompson, J. K., Lavond, D. G., \& Thompson, R. F. (1987). Initial localization of the acoustic conditioned stimulus projection system to the cerebellum essential for classical eyelid conditioning. Proceedings of the National Academy of Sciences, 84, 3531-3535.

Steinmetz, J. E., Rosen, D. J., Chapman, P. F., Lavond, D. G., \& Thompson, R. F. (1986). Classical conditioning of the rabbit eyelid response with a mossy fiber stimulation CS: I. Pontine nuclei and middle cerebellar peduncle stimulation. Behavioral Neuroscience, 100, 878-887.

Steinmetz, J. E., \& Sengelaub, D. R. (1992). Possible conditioned stimulus pathway for classical eyelid conditioning in rabbits. Behavioral and Neural Biology, 57, 103-115.

Thompson, R. F., \& Steinmetz, J. E. (2009). The role of the cerebellum in classical conditioning of discrete behavioral responses. Neuroscience, 162, 732-755.

Topka, H., Valls-Sole, J., Massaquoi, S. G., \& Hallett, M. (1993). Deficit in classical conditioning in patients with cerebellar degeneration. Brain, 116, 961-969.

Tracy, J. A., Thompson, J. K., Krupa, D. J., \& Thompson, R. F. (1998). Evidence of plasticity in the pontocerebellar conditioned stimulus pathway during classical conditioning of the eyeblink response in the rabbit. Behavioral Neuroscience, 112, 267-285.

Vogel, R. W., Amundson, J. C., Lindquist, D. H., \& Steinmetz, J. E. (2009). Eyeblink conditioning during an interstimulus interval switch in rabbits (Oryctolagus cuniculus) using picrotoxin to disrupt cerebellar cortical input to the interpositus nucleus. Behavioral Neuroscience, 123, 62-74. 
Woodruff-Pak, D. S. (1997). Evidence for the role of cerebellum in classical conditioning in humans. In J. D. Schmahmann (Ed.), The cerebellum and cognition (pp. 341-366). San Diego: Academic Press.

Woodruff-Pak, D. S., Jaeger, M. E., Gorman, C., \& Wesnes, K. A. (1999). Relationships among age, conditioned stimulusunconditioned stimulus interval, and neuropsychological test performance. Neuropsychology, 13, 90-102.

Woodruff-Pak, D. S., Papka, M., \& Ivry, R. B. (1996). Cerebellar involvement in eyeblink classical conditioning in humans. Neuropsychology, 10, 443-458.
Woodruff-Pak, D. S., \& Thompson, R. F. (1988). Classical conditioning of the eyelid response in the delay paradigm in adults aged 18-83 years. Psychology and Aging, 3, 219-229.

\section{Author Note}

This research was supported by a National Institute of Mental Health award to W.P.H. and J.E.S. (Grant R01 MH074983-01). 